\title{
STUDENT ACCEPTENCE OF LEARNING MANAGEMENT SYSTEMS: A STUDY ON DEMOGRAPHICS
}

\author{
Chet Claar, Central WashingtonUniversity, claar@cwu.edu \\ Laura Portolese Dias, Central Washington University, diasl@cwu.edu \\ Robert Shields, University of Washington, Bothell, rshields@uwb.edu
}

\begin{abstract}
This study investigates the impact of various demographic factors such as age, race, gender, and education levels on student acceptance of new learning management systems. The investigators first did a through review of the literature to find substantial increases in online learning throughout the country, University selection criteria for new Learning Management Systems (LMS), reasons for University LMS system changes, and research on UTAUT and TAM theories of technology acceptance. Then, a survey was distributed to students which measured several technology acceptance factors, utilizing the technology acceptance model (TAM). Regression analysis was performed. The results supported the following relationships between the variables: Perceived Ease of Use (PE) has a significant positive influence on perceived usefulness (PU); Perceived usefulness has a significant positive influence on attitude toward using (AT); Perceived Ease of Use (PE) has a significant positive influence on attitude toward using (AT); Perceived Usefulness (PU) has a significant positive influence on Behavioral Intentions to use (BI); Attitude toward using has a significant positive influence on behavioral intentions to use; The higher the educational level, the more likely new LMS systems will be accepted; The higher a person's age, the more likely he/she is to perceive a new LMS more negatively.
\end{abstract}

Keywords: Learning management systems, student acceptance, technology acceptance models, Canvas, Blackboard, UTAUT, TAM.

\section{OVERVIEW AND INTRODUCTION}

Given the significant increase in both the availability of, and enrollment in, on-line learning classes [21], universities are constantly asking questions that revolve around adopting new learning management system (LMS) technology. Because of the disparity in features provided by different LMS, when universities change their LMS, they could adversely affect thousands of students and faculty. One of the most important factors to consider in selecting a new LMS is student likeliness to accept the new system. This study compares demographic factors, student's likeliness and attitude to accept a new LMS. Demographic factors include age, race, level of education, and gender. As a proxy for acceptance, this study used student stated willingness to change from the existing university LMS.

\section{LITERTATURE REVIEW}

\section{Increase use of Online Learning}

A 2011 Sloan Consortium report [4], stated that 6.7 students were taking at least one online course. This increased from 570,000 students in 2010. This growth of online classes exceeds $10 \%$, while growth of regular courses was only $2 \%$ in 2010 . That year, $32 \%$ of students took at least one online course and colleges and universities listed online growth as a critical part of their long-term strategies. This increase in online course participation by students and faculty underscores the importance of using an effective LMS. Since LMS can vary greatly in usability, features, and costs, choosing one that fits all institutional stakeholders is critical. Learning Management systems can be open source or commercial. Numerous other tools could be used in an educational setting, but most are designed for K-12 or corporate training environments. Examples include Moodle, Haiku, and Litmos. Several open source LMS are available, but may not have features needed in a university setting [3]. Examples include aToutor, Canvas, Efront, Fedena, LAMS, Moodle and SWAD. The Canvas LMS has achieved significant usage in Washington State [15]. Aimed at higher education, this web-based tool offers integration of textbook cartridges, chat, calendar, and features similar to commercial products such as Blackboard. Blackboard is a widely used commercial, self-hosted service. It offers live screencasting, automatic quiz creation and grading, chat and more. Desire2Learn, another commercial LMS, offers similar features. 


\section{Common Selection Criteria in LMS Systems and Reasons for LMS change}

Prudent institutions must carefully choose the criteria used to select LMS. Elllis [9], identifies 6 main categories of LMS features:

- Centralize and automate administration

- Use self-service and self-guided services

- Assemble and deliver learning content rapidly

- Consolidate training initiatives on a scalable web based platform

- Support portability and standards

- Personalize content and enable knowledge reuse

The variety of features in each of these categories makes selection of an LMS complex. In an Education Week Article, Ash [3] lists several steps colleges and universities should take before selecting an LMS system.

- Determine overall teaching and learning structure of organization, and identify what is needed from LMS to meet these goals.

- Include a mix of various college or university stakeholders in decision process

- Participate in LMS system demonstrations by organizations, be interactive in those demonstrations

- If possible, pilot the LMS system first

- Talk to other schools using the system

- Evaluate total cost of ownership, not just the initial price

Many universities already have an LMS, there may come a time when they will need to replace it. The purchase and retirement of Angle by Blackboard caused such a re-evaluation for many institutions.

In $2010,38 \%$ of community colleges reporting in the Instructional Technology Council survey [7] planned to change their LMS system within the next few years. While existing literature does not analyze all the reasons for changing, the following appear most obvious: Cost; Ease of use and Lack of support.

The Washington State Board for Community and Technical Colleges undertook a new LMS search when Blackboard announced that it would no longer support Angel. Even though they later rescinded that, the Board moved forward with the search. They decided to adopt Canvas [15]. While such decisions often entail a comprehensive process (in this case, a 9-month process), concerns still exist regarding faculty, student, and organizational acceptance of the new Canvas LMS [7].

Some concerns may stem from the learning curve or "hassle" inflicted on faculty and students to move to a new LMS. Any system requires time to learn, and can cause content migration issues for faculty. Students may struggle initially with the new system and focus less on learning content and coursework than on adjusting to the new environment.

Despite these challenges, the reasons listed above may outweigh the cost and inertia to stay with the current system. All stakeholders can be better served if change agents understand how people accept technological change.

\section{Technology Acceptance}

Rogers' theory of Diffusion of Innovations [13] attempts to explain how various technologies are absorbed by a society. According to Rogers, diffusion is the process by which an innovation - such as a new LMS-is communicated through certain channels over time between members. Rogers' theory lists four factors affecting the spread of an innovation: the innovation itself, the types of communication channels, time, and the social system to 


\section{Issues in Information Systems \\ Volume 15, Issue I, pp. 409-417, 2014}

which the innovation is introduced. Rogers' theory was developed for consumer products, such as personal computers, and mobile phones. It has not been widely used to describe educational software adoption behavior.

Of the several theories that address individual acceptance of technology, this study, considered two prominent ones: the Unified Theory of Acceptance and Use of Technology (UTAUT) [18], [19] and the Technology Acceptance Model (TAM) [6].

The Unified Theory of Acceptance and Use of Technology (UTAUT) lists several factors which determine consumer acceptance of a new innovation [9]. They include: performance expectation, effort expectation, social influence, facilitating conditions, behavioral intention and use behavior. Each of these factors can be influenced by demographic characteristics such as gender, age, experience, and voluntariness of use.

Many studies employed the UTAUT model to study use of mobile technology [10], social media [8], and computer use [20]. Williams et al [17] addresses the number of citations for the UTAUT model (450). Their analysis determined that only 43 of the citing papers used the UTAUT model as a construct or basis for the citing authors' research. Williams et al state that while the theory may be valid, it is not used as much in practice as it appears. The UTAUT model constructs were based upon the TAM mode [16], [19].

Davis developed the Technology Acceptance Model (TAM) in the late 1980's [6]. This model lists five factors relevant in technology acceptance: perceived usefulness, perceived ease of use, actual use, behavior intention (conscious plans for future use), and attitude toward use.

Perceived usefulness measures the extent to which a person believes a particular tool will enhance his or her performance. Perceived ease of use refers to the extent of effort a person must exert in order to use a system. Behavioral intention refers to the conscious plans to use a particular technology in the future, and attitude refers to a person's perception about the actual product. The TAM model has been used to explain acceptance of the World Wide Web [11], and mobile banking [12]. Criticisms of the TAM model refer to its limited predictive power. TAM tends to focus on the individual user, and seemingly ignores the social aspect of development and diffusion of innovation [5].

With respect to student attitudes toward LMS, Adwan et.al., discuss [1], students expect value for their money. They expect online systems to be flexible, and responsive. However, a new LMS also requires faculty and students to develop new skills [2]. Because user acceptance is a primary measure of LMS implementation success [14], understanding how students accept an LMS system is an important aspect of the adoption process. If colleges and universities understand how their own demographic campus make-up could affect the acceptance of such a system, the likelihood of a successful implementation will increase.

\section{RESEARCH QUESTIONS AND HYPOTHESES}

The research questions for this study will include the following:

1. Can the Technology Acceptance Model be used to predict the acceptance of a new Learning Management System?

2. Does age impact the perception of new learning management systems?

3. Does race impact perception of new learning management systems?

4. Does educational attainment level impact perception of new learning management systems?

5. Does gender impact perception of new learning management systems?

The hypotheses for this study:

H1: Perceived Ease of Use (PE) will have a significant positive influence on Perceived Usefulness (PU).

H2: Perceived Usefulness (PU) will have a significant positive influence on attitude toward using (AT).

H3: Perceived Ease of Use (PE) will have a significant positive influence on attitude toward using (AT).

H4: Perceived Usefulness (PU) will have a significant positive influence on Behavioral Intentions to use (BI).

H5: Attitude Toward Using (AT) will have a significant positive influence on Behavioral Intentions to use (BI).

H6: Behavioral Intentions to Use (BI) will have a significant positive influence on actual use (AU).

H7a: Age will have a significant influence on Perceived Usefulness. 
H7b: Age will have a significant influence on Perceived Ease of Use.

H8a: Race will have significant influence on Perceived Usefulness.

H8b: Race will have a significant influence on Perceived Ease of Use.

H9a: Gender (GEN) will have significant influence on Perceived Usefulness.

H9b: Gender (GEN) will have a significant influence on Perceived Ease of Use.

H10a: Educational level (EDU) will have significant influence on Perceived Usefulness.

H10b: Education level (EDU) will have a significant influence on Perceived Ease of Use.

\section{STUDY DESIGN}

The investigators obtained approval in January 2014 from the Human Subjects Research Committee at a Northwest University, where the study took place. The measurement instrument was developed based on items in the cited literature. Although the UTAUT model is more recent, this survey was based primarily on the TAM model because of its it is widely accepted in the field for the measurement of individual computer users, and was developed to explain or predict user acceptance of technology, which makes it a viable model to utilize for this study. Figure 1 shows the TAM acceptance factor that prompted each survey question. Appendix 1 shows the survey instrument used for collection of data.

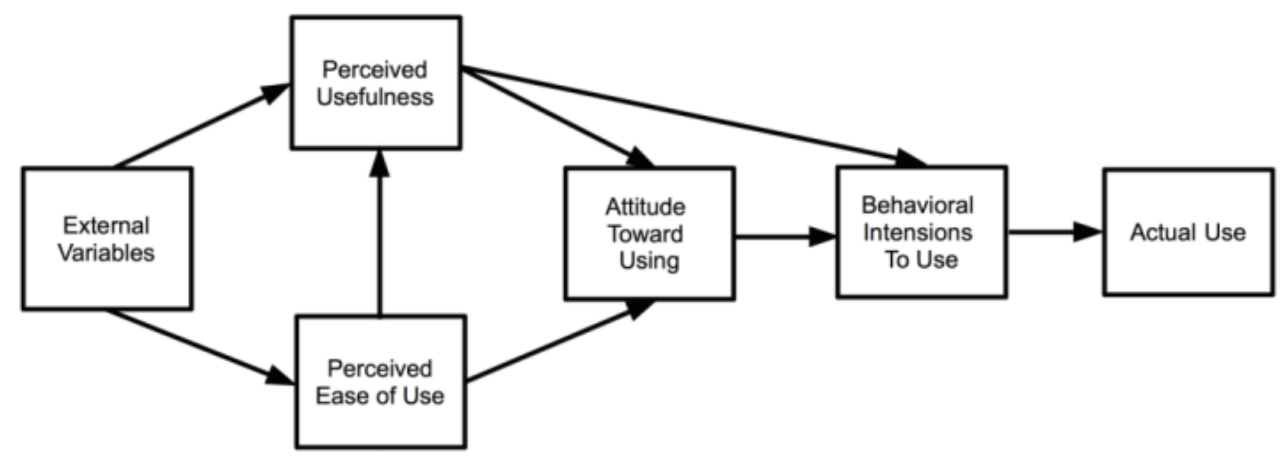

Figure 1. Technology Acceptance Model (Davis et al., 1989)

The demographic questions included age, race, gender, and level of education. The answers to these questions will be used to compare new LMS acceptance questions later in the study. The presentation order of questions was varied to gather data for future research comparing order demographic questioning.

The investigators used a seven point Likert scale to offer a larger range of attitudes. For some of the questions, a simple yes or no answer sufficed. In order to prevent student major bias, the survey was distributed to the entire student population of a Western U.S. University using the campus email system. An email was sent to students in May 2014 asking them to take the survey. A follow-up email with a link to the survey was sent a few days later. Data was collected using Survey Monkey. Survey Monkey allows the researchers to require participants to enter a passcode in order to access the survey. No identifying information was collected, other than the above noted demographic information.

\section{RESULTS}

Multiple regression analyses was used to test the research hypotheses listed previously. The following tables address sample characteristics, construct descriptive statistics and the regression results for this study. 
Issues in Information Systems

Volume 15, Issue I, pp. 409-417, 2014

Table 1. Sample Characteristics

\begin{tabular}{lll}
\hline Categorical Variable & Frequency & Percent \\
\hline Gender & & \\
\hline Male & 154 & 35.3 \\
Female & 275 & 63.1 \\
Total & 429 & 98.4 \\
\hline Race & & \\
\hline American Indian or Alaska Native & 6 & 1.4 \\
Hawaiian or Other Pacific Islander & 6 & 1.4 \\
Asian or Asian American & 30 & 6.9 \\
Black or African American & 17 & 3.9 \\
Hispanic or Latino & 35 & 8.0 \\
Non-Hispanic White & 335 & 76.8 \\
\hline Education Level & 25.7 & \\
\hline High school or equivalent & 9.808 & \\
Some college & 22 & 5.0 \\
Career training & 208 & 47.7 \\
2-year college degree & 2 & .5 \\
4-year college degree & & \\
\hline Total & & \\
Missing & & \\
\hline Continuous Variable & & \\
\hline Age & & \\
Mean & & \\
\hline Standard Deviation & & \\
\hline
\end{tabular}


Table 2. Construct Descriptive Statistics

\begin{tabular}{lccccccccc}
\hline Variable & $\mathrm{N}$ & Min & Max & Mean & Std. Dev. & Skew & Std. Err. Kurtosis & Std. Err. \\
\hline Behavioral Intention & 435 & 1.00 & 7.00 & 4.3995 & 1.99130 & -.245 & .118 & -1.194 & .235 \\
Ease of Use & 428 & 1.00 & 7.00 & 4.8855 & 1.63987 & -.598 & .118 & -.559 & .235 \\
Perceived Usefulness & 428 & 1.00 & 7.00 & 5.2185 & 1.43625 & -.744 & .118 & .041 & .235 \\
Attitude Towards Using & 428 & 1.00 & 7.00 & 4.6542 & 1.62556 & -.414 & .118 & -.652 & .235 \\
Valid N (listwise) & 426 & & & & & & & & \\
\hline
\end{tabular}

Table 3. Regression Results

\begin{tabular}{|c|c|c|c|}
\hline & & Coefficients ( $\beta$ ) & Result \\
\hline H1 & $\mathrm{PE} \Rightarrow \mathrm{PU}$ & $.902 * * *$ & Supported \\
\hline $\mathrm{H} 2$ & $\mathrm{PU} \Rightarrow \mathrm{AT}$ & $.905^{* * *}$ & Supported \\
\hline $\mathrm{H} 3$ & $\mathrm{PE} \Rightarrow \mathrm{AT}$ & $.915^{* * *}$ & Supported \\
\hline H4 & $\mathrm{PU} \Rightarrow \mathrm{BI}$ & $.844 * * *$ & Supported \\
\hline H5 & $\mathrm{AT} \Rightarrow \mathrm{BI}$ & $.874 * * *$ & Supported \\
\hline H6 & $\mathrm{BI} \Rightarrow \mathrm{AU}$ & $-.177 * * *$ & Not Supported \\
\hline H7A & Age $\Rightarrow$ PU & $.101 *$ & Supported \\
\hline H7B & Age $\Rightarrow$ EU & .055 & Not Supported \\
\hline $\mathrm{H} 8 \mathrm{~A}$ & Race $\Rightarrow$ PU & .028 & Not Supported \\
\hline H8B & Race $\Rightarrow$ EU & .055 & Not Supported \\
\hline H9A & Gender $\Rightarrow$ PU & .034 & Not Supported \\
\hline H9B & Gender $\Rightarrow$ EU & .024 & Not Supported \\
\hline $\mathrm{H} 10 \mathrm{~A}$ & $\mathrm{EDU} \Rightarrow \mathrm{PU}$ & $.152 * *$ & Supported \\
\hline $\mathrm{H} 10 \mathrm{~B}$ & $\mathrm{EDU} \Rightarrow \mathrm{EU}$ & $.129 * *$ & Supported \\
\hline
\end{tabular}

$* \mathrm{p} \leq 0.05 ; * * \mathrm{p} \leq 0.01 ; * * \mathrm{p} \leq 0.001$

\section{POSSIBLE VALIDITY ISSUES AND LIMITATIONS}

Internal validity issues may arise from the possible bias in student answers based on social desirability. In addition, the wording of the questions, ordering of the questions, use of the Likert scale and other often cited issues associated with the instrument could have impacted the study.

Additional internal validity issues may stem from respondents discomfort in using a web based tool, outside of the University system. In addition, the response rate of 429 may not provide a sufficient representation of the population, nor equal representation of gender and race. A majority of respondents were female $(\mathrm{n}=275$ or $63 \%)$, with a larger percentage of non-Hispanic white respondents $(n=335$ or $76.8 \%)$. The survey was also based on the TAM model. Using the UTAUT model may have yielded a different model fit.

External validity limitations include the generalizability of the study. The student sample results may not adequately represent the general population of students. In addition, the timing of the study may not be appropriate, given the University had already made the decision to transition to the Canvas LMS when the survey was distributed. 


\section{DISCUSSION AND RECOMMENDATIONS}

The regression analysis provided insight into relationships between variables from the TAM model perspective. It appears most of the TAM model variables are relationship dependent, for example, perceived ease of use does impact perceive usefulness. Likewise, perceived usefulness and ease of use does impact attitude toward using. The perceive usefulness does impact behavioral intentions as well. While most of the hypotheses related to the TAM model are supported by this study, the surprising exception is H6. One would expect behavioral intention to use would positively impact actual use. The regression analysis found this is not the case. Possible reasons for this could include student disappointment with actual use, or lack of actual use. In addition, because students do not actually have a choice to use the LMS system, behavioral intention relationships could have been skewed.

Regression analysis showed few demographic variable relationships. Of the analysis, the only relationships found were: age and perceived usefulness; education and perceived usefulness; and education and ease of use. Reasons for this might include the greater the age, the greater the understanding and importance of usefulness, or concern with usefulness. It is possible younger generations have less concern about usefulness, given the vast experience with technology. It is possible the less education, the more concern a student may have for ease of use. While the more educated, there is an assumption and confidence from the student to navigate a new system.

Gender and race did not impact any of the TAM variables, therefore $\mathrm{H} 8$ and $\mathrm{H} 9$ are accepted, as the investigators did not expect either of these variables would influence acceptance of a LMS.

The implications and significance of this study can be important to both LMS providers as well as universities. When universities are marketing and surveying students for use of a new learning management system, they should focus their efforts on ease of use and usefulness of the new system, as opposed to focus marketing efforts in less importance areas. Attitude toward using, actual use, and behavioral intention to use should be secondary marketing efforts. In addition, LMS's should focus their orientation materials on ease of use and usefulness for maximum acceptance of their technology.

\section{FUTURE AREAS OF STUDY}

Future variations might include a larger sample, including several different Universities. In addition, studies could compare community college and university students nationwide. A number of possible could examine in more depth the effect of demographics on the TAM model for other types of educational technology. Comparing survey results based on both the TAM and UTAUT models could be enlightening. Additional areas of study could include comparing a variety of majors to investigate if some majors are more likely to accept new technology as part of the LMS system. A possible study could take a different direction and look at faculty acceptance of LMS systems, and from the perspective of the administrator. Future research could collect attitudinal acceptance data with open ended questions such as, "What LMS feature(s) seem most important to you and why? The importance of how and why students accept LMS systems can assist faculty and administrators with development of communication plans and better understanding of student needs.

\section{REFERENCES}

[1] Al-Adwan, A., \& Smedley, J. (2013). Exploring students acceptance of e-learning using Technology Acceptance Model in Jordanian universities. Applied Science University, Jordan. International Journal of Education and Development using Information and Communication Technology, 9(2), 4-18.

[2] Al-Adwan, A., \& Smedley, J. (2013). Exploring students acceptance of e-learning using Technology Acceptance Model in Jordanian universities. Applied Science University, Jordan. International Journal of Education and Development using Information and Communication Technology, 9(2), 4-18.

[3] Ash, K. (June 11, 2013), How to choose the right learning management system, Education Week. Retrieved from: http://www.edweek.org/dd/articles/2013/06/12/031ms-evaluation.h06.html

[4] Babson Survey Research Group, (2012). Retrieved from http://www.onlinelearningsurvey.com/highered.html

[5] Bagozzi, R.P. (2007), "The legacy of the technology acceptance model and a proposal for a paradigm shift.", Journal of the Association for Information Systems 8(4): 244-254. 


\section{Issues in Information Systems \\ Volume 15, Issue I, pp. 409-417, 2014}

[6] Davis, F. D. (1989), "Perceived usefulness, perceived ease of use, and user acceptance of information technology", MIS Quarterly, 13(3): 319-340

[7] 2010 Distance Education Survey Results (2010). Instructional Technology Council. Retrieved from: http://www.itcnetwork.org/

[8] Eckhardt,A. Laumer, S. and Weitzel,T. "Who influences whom? Analyzing workplace referents' social influence on IT adoption and non-adoption," Journal of Information Technology, vol. 24, no. 1, pp. 11-24, 2009

[9] Ellis, R.K. (2009), Field Guide to Learning Management Systems, ASTD Learning Circuits

[10] Koivimäki, A. Ristola, and M. Kesti, "The perceptions towards mobile services: An empirical analysis of the role of use facilitators," Personal \& Ubiquitous Computing, vol. 12, no. 1, pp. 67-75, 2008

[11] Lederer, A. L., Maupin, D. J., Sena, M. P., \& Zhuang, Y. (2000). The technology acceptance model and the World Wide Web. Decision support systems, 29(3), 269-282.

[12] Lule, I., Omwansa, T. K., \& Waema, T. M. (2012). Application of Technology Acceptance Model (TAM) in M-Banking Adoption in Kenya. In International journal of computing and ICT research. Presented during the Africa mobile money research conference.

[13] Rogers, E. M. (2003). Diffusion of innovations (5th edition). New York, NY: Free Press.

[14] Saadé, R., \& Bahli, B. (2005). The impact of cognitive absorption on perceived usefulness and perceived ease of use in on-line learning: an extension of the technology acceptance model. Information \& Management, 42(2), 317-327.

[15] Schaffhauser, D. (May 24, 2012). "Washington State higher ed shifting to instructure Canvas." Campus Technology. Retrieved from: http://campustechnology.com/articles/2012/05/24/washington-state-higher-ed-shiftingto-instructure-canvas.aspx?=CTEL

[16] Sundravej, T. (2010). Empirical Validation of Unified Theory of Acceptance and Use of Technology Model. Journal of Global Information Technology Management. 13 (1), 5-27.

[17] Williams, M. D., Rana, N. P., Dwivedi, Y. K., \& Lal, B. (2011). Is UTAUT really used or just cited for the sake of it? a systematic review of citations of UTAUT's originating article. In ECIS.

[18] Viswanath, V. ;Morris,M.G.; Davis, G.B.; Fred F.D., "User acceptance of information technology: Toward a unified view", MIS Quarterly, 2003, 27, 3, 425-478.

[19] Venkatesh, V., Thong, J. Y. L., \& Xu, X. (2012). Consumer Acceptance and Use of Infotrmtion Technology: Extending the Unified Theory of Acceptance and use of Technology. MIS Quarterly, 36, 1, 157-178.

[20] Verhoeven, J.C, Heerwegh, D. and De Wit, K. "Information and communication technologies in the life of university freshmen: An analysis of change," Computers \& Education, vol. 55, no. 1, pp. 53-66, 2010

[21] Zha, S., \& Otendorfer L., C. (2011). Effects of peer lead online asynchronous discussion on undergraduate students' cognitive achievement, American Journal of Distance Education, 25, (4), 238-253. Retrieved from http://www.tandfonline.com/doi/pdf/10.1080/08923647.2011.618314

\section{Survey Questions}

\section{APPENDIX 1}

1. What is your age? (demographic) \{textbox entry\} whole number between 18 and 100

2. What is the gender you most closely identify with? (demographic): Choices: Male, Female

3. What is your race? (demographic) Choices: American Indian or Alaska Native Asian Black or African American; Native Hawaiian or Other Pacific Islander White/Caucasian

4. What is the highest level of education you have completed? (demographic)Less than high school; High school or equivalent; Some college; Career training; 2-year college degree; 4-year college degree (BA, BS, etc.); Master's degree (MA, MS, MBA, etc.); Doctoral Degree (Ph.D., Ed.D., DBA, etc.); Professional Degree (MD, JD, DDS, DVM, etc.)

5. If you are a current undergraduate or graduate student, please indicate what year you currently in: (demographic) Undergraduate Freshman; Undergraduate; Sophomore; Undergraduate; Junior; Undergraduate Senior; Graduate $1^{\text {st }}$ year; Graduate $2^{\text {nd }}$ year; Graduate $3^{\text {rd }}$ year; Does not apply 


\section{Issues in Information Systems \\ Volume 15, Issue I, pp. 409-417, 2014}

6. The learning management system you use (i.e. Blackboard or Canvas) is useful in completing your online/hybrid class work (perceived usefulness) Highly agree; Agree; Somewhat agree; Neutral or have not used Canvas; Somewhat disagree; Disagree; Highly disagree

7. If you could use Blackboard or Canvas as your only learning management system, which would you choose? (behavioral intention): Canvas; Blackboard; Neither

8. Canvas is easy to use. (ease of use): Highly agree; Agree; Somewhat agree; Neutral or have not used Canvas; Somewhat disagree; Disagree; Highly disagree

9. Canvas provides better features than previous systems used (such as Blackboard) (perceived usefulness): Highly agree; Agree; Somewhat agree; Neutral or have not used Canvas; Somewhat disagree; Disagree; Highly disagree

10. In my experience using canvas, the system has been useful. (perceived usefulness): Highly agree; Agree; Somewhat agree; Neutral or have not used Canvas; Somewhat disagree; Disagree; Highly disagree

11. If given the choice between a Canvas course and a Blackboard course, I would you be more inclined to use Canvas. (behavioral intention): Highly agree; Agree; Somewhat agree; Neutral or have not used Canvas; Somewhat disagree; Disagree; Highly disagree

12. I would be more likely to sign up for a class that uses Canvas as opposed to Blackboard. (behavioral intention): Highly agree; Agree; Somewhat agree; Neutral or have not used Canvas; Somewhat disagree; Disagree; Highly disagree

13. I have taken one or more courses using Canvas (actual system use): yes; no

14. My experience using Canvas has been positive. (attitude toward using): Highly agree; Agree; Somewhat agree; Neutral or have not used Canvas; Somewhat disagree; Disagree; Highly disagree

15. I believe everyone should use Canvas. (attitude toward using) Highly agree; Agree; Somewhat agree; Neutral or have not used Canvas; Somewhat disagree; Disagree; Highly disagree

16. Using the features of Canvas (navigation, turning in assignments, finding feedback) is easy to figure out. (ease of use) Highly agree; Agree; Somewhat agree; Neutral or have not used Canvas; Somewhat disagree; Disagree; Highly disagree

17. Use of the current learning management system impacted my grade positively in class: (attitude toward use) Highly agree; Agree; Somewhat agree; Neutral or have not used Canvas; Somewhat disagree; Disagree; Highly disagree

18. The current Learning Management System is improved over the last one I used: (perceived ease of use): Highly agree; Agree; Somewhat agree; Neutral or have not used Canvas; Somewhat disagree; Disagree; Highly disagree

19. My professors do not require me to use a Learning Management System (i.e. Blackboard, Canvas) (Voluntariness of Use): Highly agree; Agree; Somewhat agree; Neutral or have not used Canvas; Somewhat disagree; Disagree; Highly disagree 